\title{
Low-level laser treatment of burning mouth syndrome: a systematic review and meta-analysis
}

\author{
Chen Sun ${ }^{1,2,3}$, Wei-Wen Jiang ${ }^{1,2,3}$ \\ ${ }^{1}$ Department of Oral Mucosal Diseases, Shanghai Ninth People's Hospital, College of Stomatology, Shanghai Jiao Tong University School of \\ Medicine, Shanghai 200011, China; ${ }^{2}$ National Clinical Research Center for Oral Diseases, Shanghai 200011, China; ${ }^{3}$ Shanghai Key Laboratory of \\ Stomatology \& Shanghai Research Institute of Stomatology, Shanghai 200011, China \\ Contributions: (I) Conception and design: All authors; (II) Administrative support: All authors; (III) Provision of study material or patients: All authors; \\ (IV) Collection and assembly of data: All authors; (V) Data analysis and interpretation: All authors; (VI) Manuscript writing: All authors; (VII) Final \\ approval of manuscript: All authors. \\ Correspondence to: Wei-Wen Jiang. Department of Oral Mucosal Diseases, Shanghai Ninth People's Hospital, College of Stomatology, Shanghai Jiao \\ Tong University School of Medicine, 639 Zhi-Zao-Ju Road, Shanghai 200011, China. Email: wwjiang33@hotmail.com.
}

\begin{abstract}
Burning mouth syndrome (BMS) is a chronic disease that consists of pain or a burning sensation on the oral mucosa in the absence of clinical or laboratory signs. The aim of this study was to compare the efficacy of low-level laser (LLL) treatment with different wavelengths on patients with BMS to provide an optimized approach for clinical management. The PubMed and Wanfang databases were searched for studies in English or Chinese until September 30, 2018 using "burning mouth syndrome" and "laser" as keywords. Fifteen clinical trials were analyzed for data extraction. LLL treatment for BMS was effective. A LLL with a wavelength of $790 \mathrm{~nm}$ showed the greatest efficiency. However, the parameters in the trials, such as wavelength $(650-980 \mathrm{~nm})$, power $(20-1,500 \mathrm{~mW})$, energy density $\left(0.53-200 \mathrm{~J} / \mathrm{cm}^{2}\right)$, time $(10 \mathrm{~s}-$ $15 \mathrm{~min}$ ), sessions (1-20 s), and irradiated frequency, varied widely. More randomized controlled trials (RCTs) are needed to draw a clear conclusion to provide evidence for optimized clinical management.
\end{abstract}

Keywords: Burning mouth syndrome (BMS); low-level laser (LLL)

Received: 30 June 2019; Accepted: 15 October 2019; Published: 29 November 2019.

doi: $10.21037 /$ fomm.2019.10.02

View this article at: http://dx.doi.org/10.21037/fomm.2019.10.02

\section{Introduction}

Burning mouth syndrome (BMS) is a chronic intraoral pain disorder with numbness or a burning or tingling sensation where no medical or dental cause can be identified $(1,2)$. Patients with BMS possibly have mucosa dryness or taste alteration (3). The symptoms of BMS trends to increase from day to night and could be occurred on the tongue, lip or the entire oral mucosa. BMS is seen more frequently in pre- and postmenopausal women $(4,5)$. The etiology of BMS is not clear, and the therapy is aimed at relieving symptoms (6-9). Evidence has shown that $\mathrm{BMS}$ is associated with peripheral or central neuropathic disturbances (10). Clonazepam and antidepressants have reduced the symptoms of pain and burning sensation for patients with BMS (10). Recently, the use of low-level laser (LLL) treatment has been used to reduce pain and burning sensation in patients with BMS.

Biological effects occur in organisms under the influence of LLL therapy. LLL therapy has the potential to reduce pulpal inflammation, preserve dental pulp vitality and improve healing (11-16). LLL produces an analgesic effect by decreasing endogenous opiates, increasing the pain threshold and regulating the release of pain mediators, such as bradykinin and histamine (17-20). Sugaya et al. reported that $46.2 \%$ of patients with BMS benefited from LLL with $790 \mathrm{~nm}, 20 \mathrm{~mW}$, and $6 \mathrm{~J} / \mathrm{cm}^{2}$ (21). Likewise, ArbabiKalati et al. showed that laser group with $630 \mathrm{~nm}, 30 \mathrm{~mW}$, and $1 \mathrm{~J} / \mathrm{cm}^{2}$ on symptom relief was superior to placebo 
group (20). Although Al-Maweri et al. reviewed 10 clinical trials of LLL treatment and concluded that majority of the studied showed effective in reducing symptom of BMS, the parameters of LLL in those studies were widely variable (3). Our study updated the clinical trials of LLL treating BMS till September 30, 2018 and was focused on the treating parameters of LLL therapy patients with BMS.

\section{Methods}

\section{Criteria for considering studies for this review}

All clinical trials using LLL treating patients with BMS were included.

The type of studies was clinical trial. The type of participants was patients diagnosed with BMS. The intervention was LLL with or without placebo. The outcome was measured by relief of pain/burning sensation.

\section{Search methods for identification of studies}

A literature search was conducted in the PubMed and Wanfang databases until September 30, 2018 by using the following keywords: "BMS" and "laser". Studies could be in either Chinese or English. The titles and abstracts were screened from the initial searches to select trials for treating the local oral mucosa on BMS patients with LLL. The full report was screened and assessed when inadequate information of the titles and abstracts was hard to decide whether a trial fulfilled the inclusion criteria.

\section{Data collection and analysis}

The data collected included author, year of publication, participants, assessment criteria, effect, wavelength of LLL therapy, power, irradiation session, energy density, time and irradiation frequency. The treatment efficiency was calculated as [visual analog scale (VAS) baseline - VAS final session]/VAS baseline. If the trial did not mention the baseline of VAS, the treatment efficiency was analyzed as the number of improved patients/numbers of total patients. RevMan version 5.3 was used to perform meta-analysis. The heterogeneity acrossing studies was analyzed by the $\mathrm{I}^{2}$ statistic, whose value of $25 \%, 50 \%$, and $75 \%$ corresponding to low, moderate, and high heterogeneity, respectively (22). If $\mathrm{I}^{2}>25 \%$, a sensitivity analysis was conducted to explore the source of significant heterogeneity (23).

\section{Assessment of quality}

The quality of randomized controlled trial (RCT) was assessed following the Cochrane Collaboration's tool for 7 aspects of bias, including random sequence generation (selection bias), allocation concealment(selection bias), blinding of participants and personnel (performance bias), blinding of outcome assessment (detection bias), incomplete outcome data (attrition bias), selective reporting (reporting bias), and others bias (6). The overall risk of bias following these criteria: when having all low risk of bias, the RCT was deemed as an overall low risk of bias; when having at least one unclear risk of bias and had no high risk of bias, the RCT was deemed to have an unclear overall risk of bias; when having a high risk of bias, the RCT was deem as an overall high risk of bias.

\section{Results}

\section{The search}

The initial search yielded a total of 36 studies from all databases. Of 36 articles, no articles were removed after screening for duplication. A total of 11 articles were excluded after reading the titles and abstracts, and the fulltext articles of the remaining 25 studies were reviewed. At this full-text analysis, 10 studies were excluded because they did not meet our inclusion criteria. A total of 15 studies were processed for final review and meta- analysis (20,21,24-36). The process of study selection is described in Figure 1.

\section{Included studies}

Six of the 15 studies were randomized trials with 101 participants (25-30). Nine studies were RCTs with 427 participants (20,21,24,31-36). Among the RCTs, 8 RCTs compared the efficacy between the LLL group and the placebo group, which consisted of a laser with no energy (20,21,31-36) and 1 RCT compared the effects of the LLL group and the clonazepam group (24).

\section{Characteristics of participants}

All participants were diagnosed with BMS, which is persistent oral mucosal pain with no dental or medical cause. In total, 451 women (85.4\%) and 77 men (14.6\%) were included. The mean age for trials was ranged from 46.9 to 70.9 years (Table 1). 


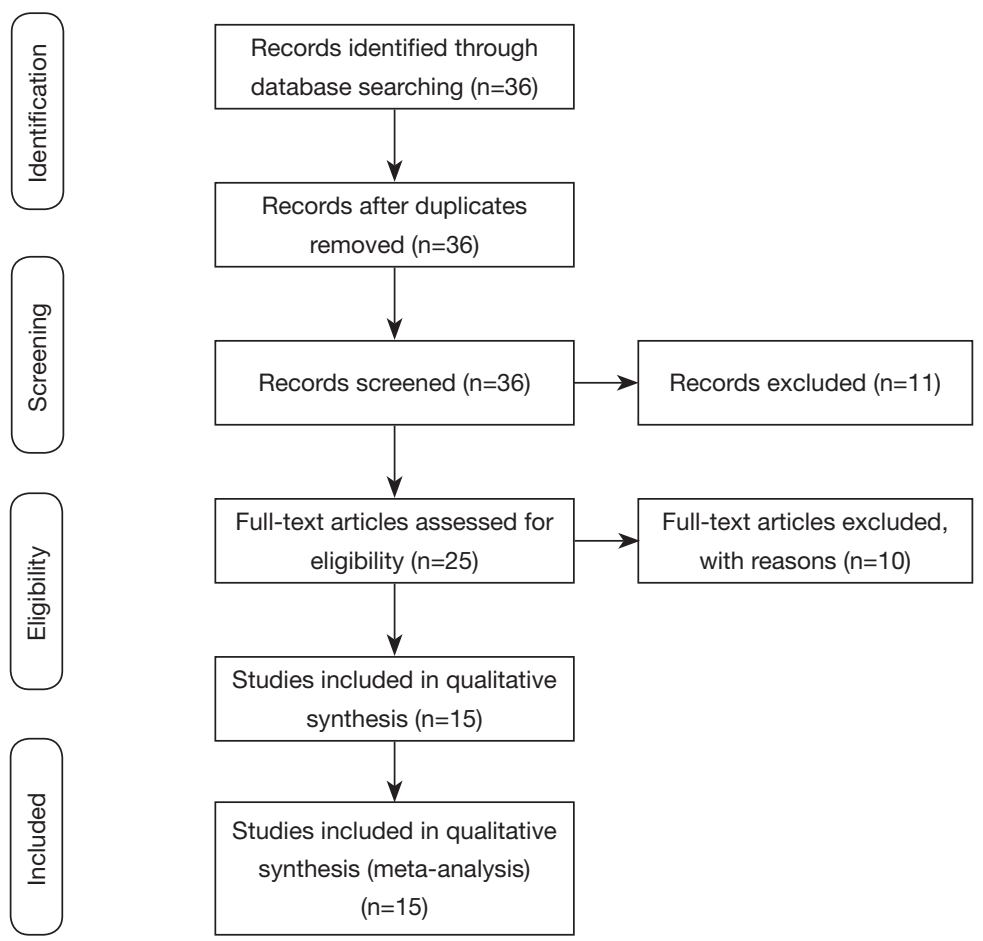

Figure 1 Flow chart of progress for systematic review.

Table 1 General characteristics of subjects

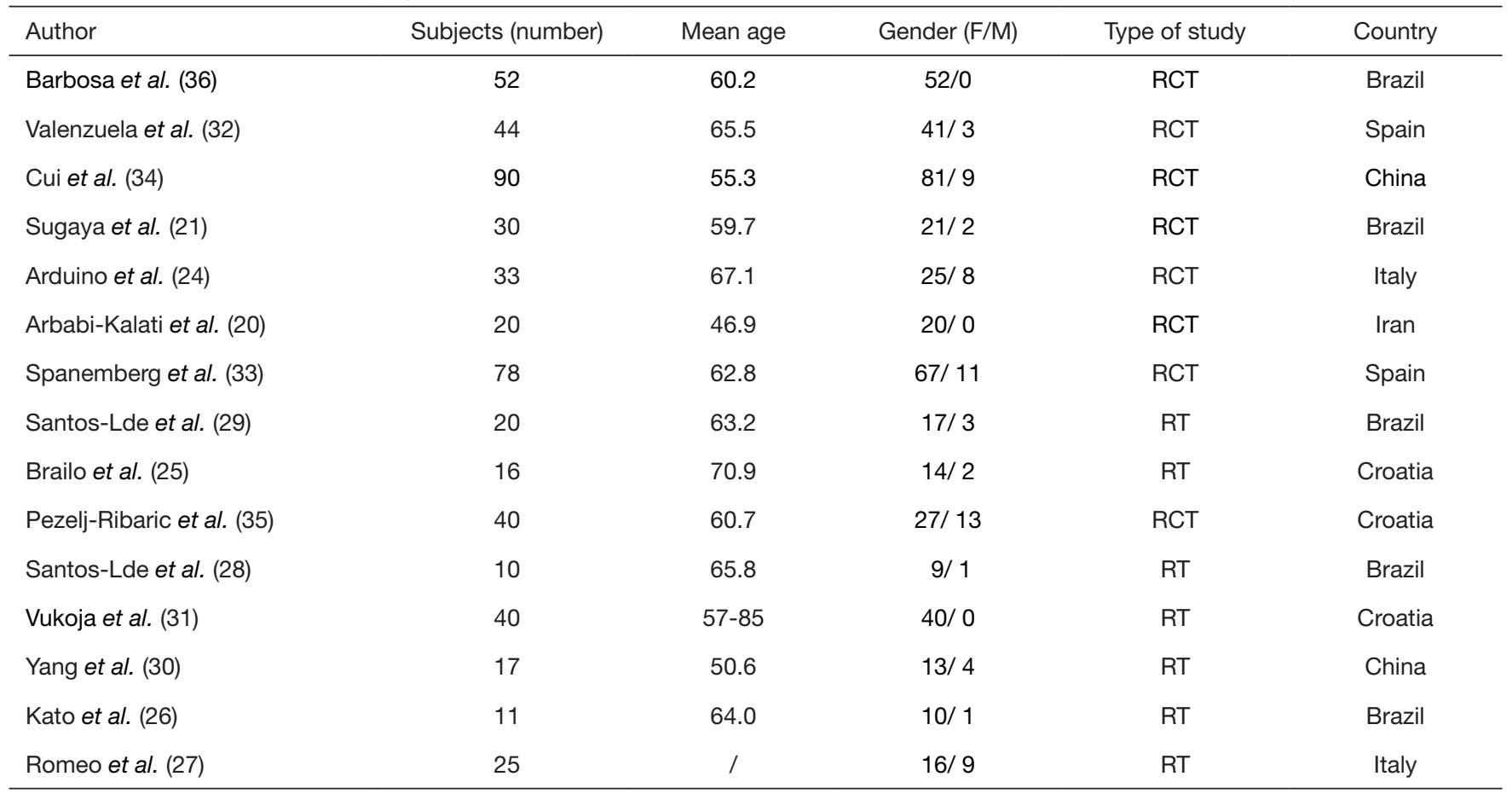

$\mathrm{RCT}$, randomized controlled trial; RT, randomized trial. 
Table 2 Parameters of LLL treatment for patients with BMS

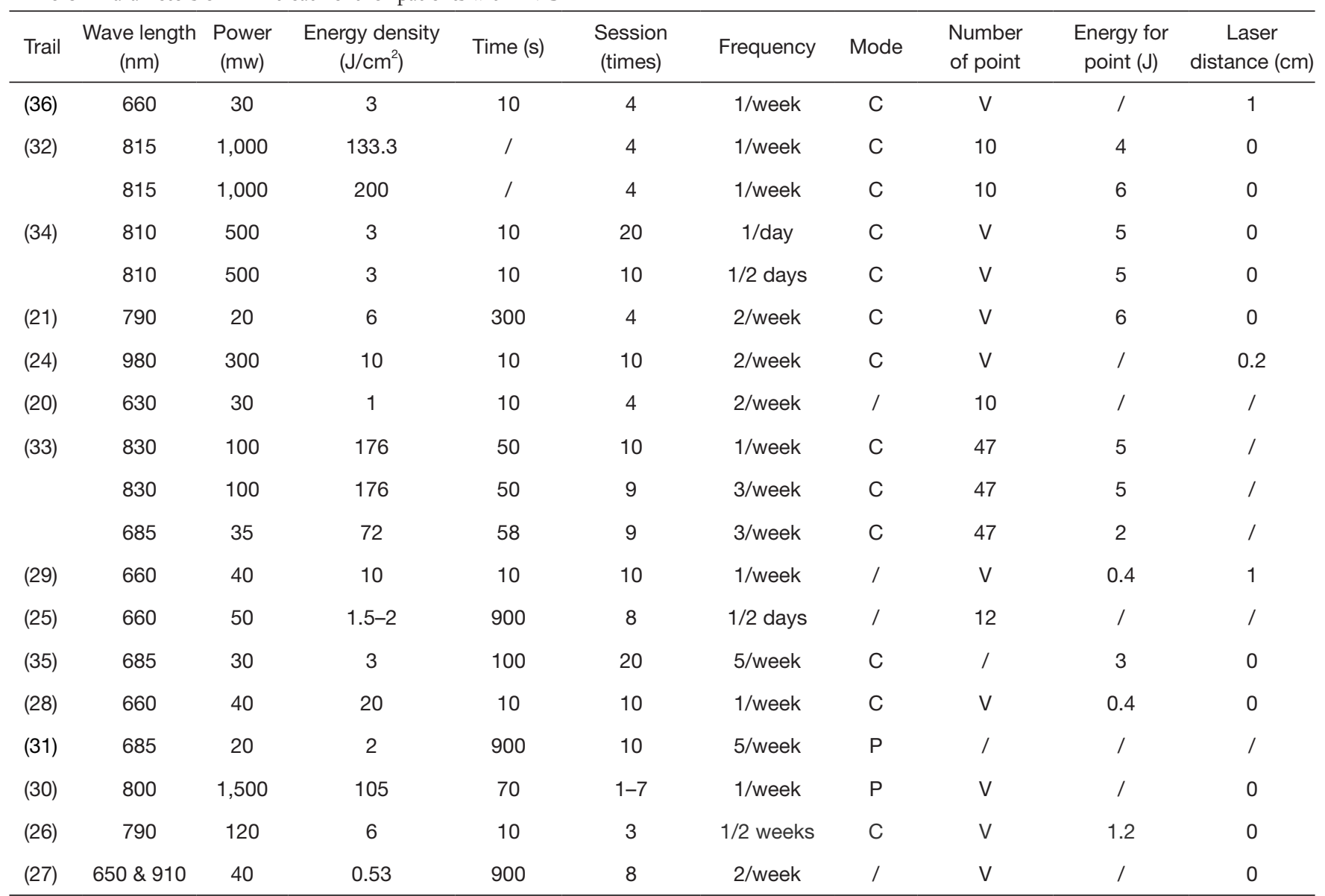

C, continuous; P, pulsed; V, variable according to irradiated area.

\section{Parameters of intervention}

All trials used a diode laser. The parameters of LLL therapy varied widely with the wavelength of laser, power, energy density, irradiation times, irradiation sessions, mode, number of point, energy for point, and laser distance (Table 2). Fourteen trials used unitary wavelengths $(20,21,24-$ 26,28-36). A double gallium arsenide (GaAs) laser with wavelengths of 650 and $910 \mathrm{~nm}$ was utilized in one study (27). Four trials used the same wavelength of $660 \mathrm{~nm}$ and similar other parameters, and the greatest improvement was $58.2 \%$ $(25,28,29,36)$. The irradiation time ranged from $10 \mathrm{~s}$ to 15 min. One study did not mention the time of irradiation (23). The participants in 14 trials received constant sessions (20,21,24-29,31-36). The treatment session number in Yang et al. ranged from 1 to 7 , and treatment ended when patients felt they no longer needed treatment (30).

\section{Relief of pain or burning sensation}

All 15 trials were evaluated the reduction of pain on patients with BMS. Thirteen of these trials used the VAS to evaluate pain relief (Table 3) (21,24-26,28-36). The numeric rating scale (NRS) was applied in 2 trials (Table 3) $(20,27)$. Fifteen trials showed $15.6 \%$ to $80.4 \%$ relief of pain or burning sensation after LLL treatment. The clinical trial by Kato et al. with $790 \mathrm{~nm}$ wavelength and energy density $6 \mathrm{~J} / \mathrm{cm}^{2}$ showed the greatest efficiency (Table 3) (26). Eight out of 9 RCTs showed significant differences between LLL therapy and controls (Table 3) (20,21,24,31-34,36).

Four studies were qualified for meta-analysis using a random-effects model (20,22-24). The effect of LLL treatment was found significantly higher than placebo (standard mean difference, 2.32; 95\% CI, 1.17 to 3.46). However, we found significant heterogeneity across 
Table 3 Efficacy and adverse reaction of LLL treatment for patients with BMS

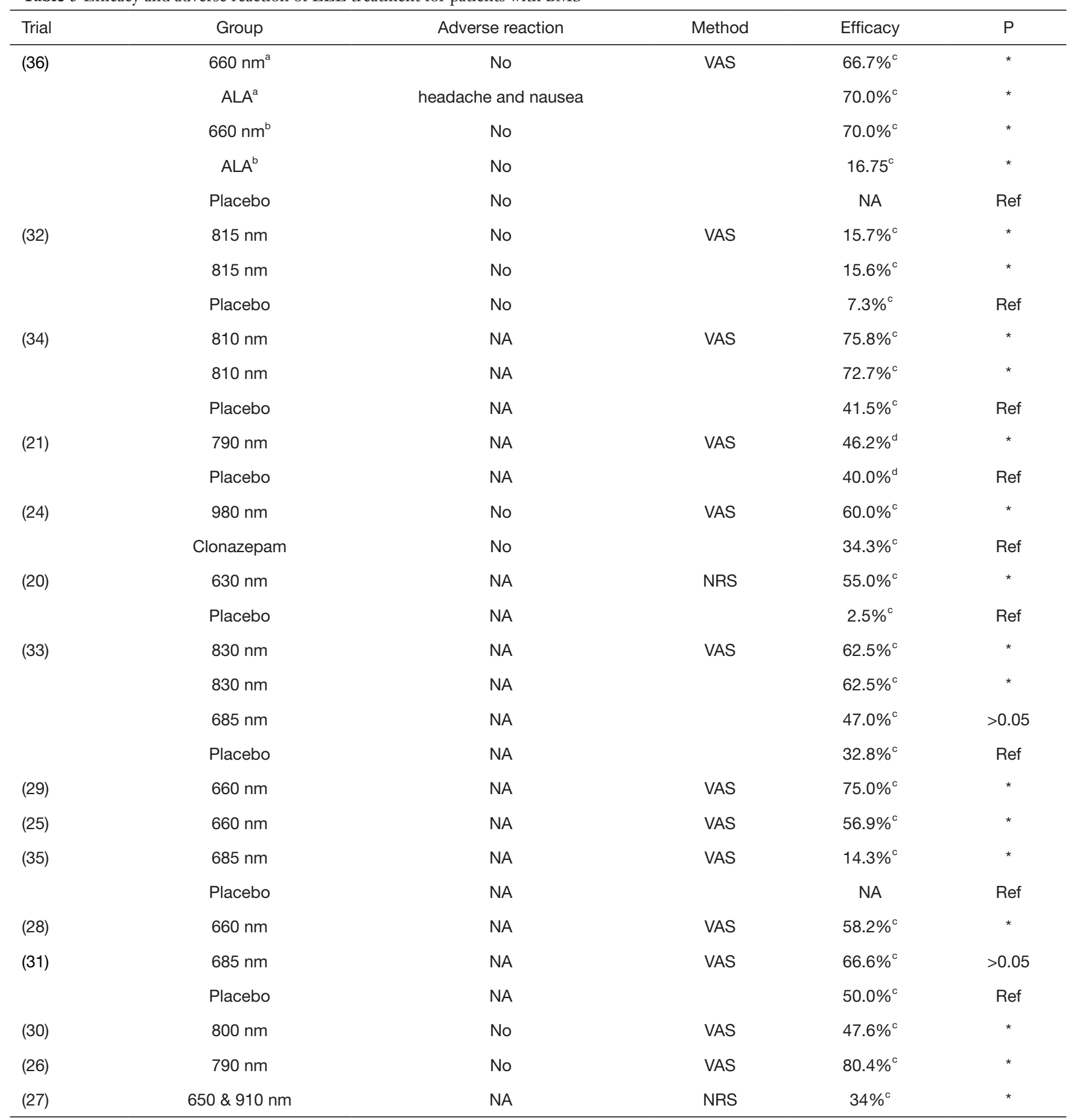

${ }^{a}$, burning mouth syndrome; ${ }^{b}$, secondary oral burning; ${ }^{c}$, compared with baseline; ${ }^{d}$, compared with no baseline; ${ }^{*},<0.05$. ALA, alpha-lipoic acid; Ref, reference; NA, not available. 


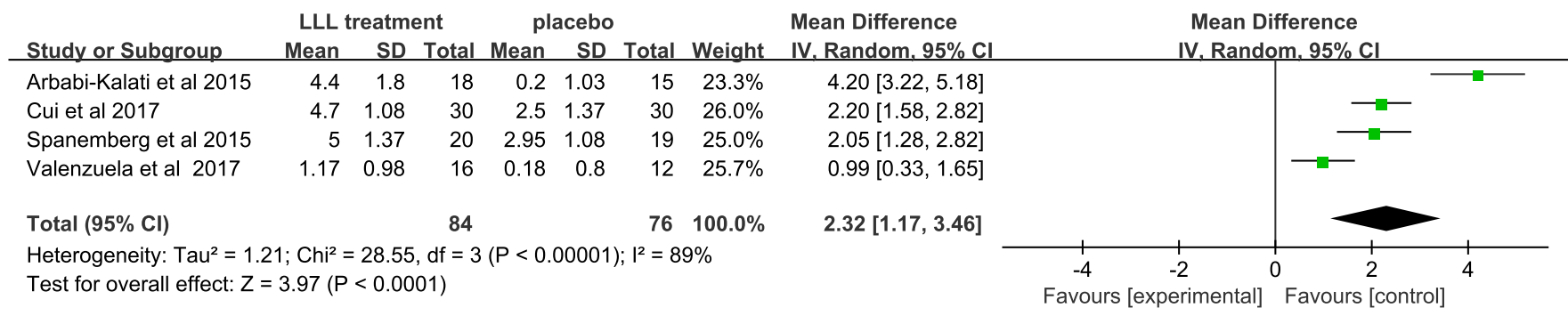

Figure 2 Summary of bias risk. L, low risk of bias; U, unclear risk of bias; H, high risk of bias.

\begin{tabular}{|c|c|c|c|c|c|c|c|}
\hline & 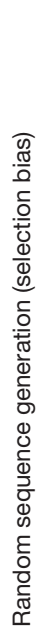 & 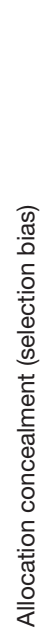 & 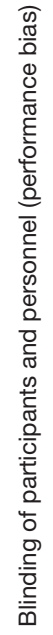 & 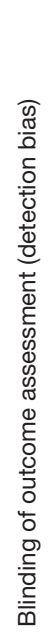 & 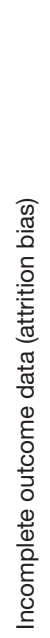 & 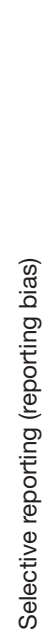 & 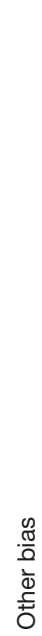 \\
\hline Arbabi-Kalati 2015 & L & L & L & L & L & $\mathrm{L}$ & $\mathrm{L}$ \\
\hline Arduino 2016 & L & L & L & L & L & L & L \\
\hline Barbosa 2018 & L & L & $\mathrm{L}$ & L & $\mathrm{H}$ & $\mathrm{L}$ & L \\
\hline Cui 2017 & L & U & $\mathrm{L}$ & $U$ & L & $\mathrm{L}$ & L \\
\hline Pezeli-Ribaric 2013 & U & U & U & L & L & L & L \\
\hline Spanemberg 2015 & L & U & U & U & L & $L$ & L \\
\hline Sugaya 2016 & L & L & $\mathrm{L}$ & L & L & L & L \\
\hline Valenzuela 2017 & L & L & L & $\mathrm{L}$ & L & L & L \\
\hline Vukoja 2011 & L & $U$ & $\mathrm{H}$ & $U$ & L & $U$ & $\mathrm{H}$ \\
\hline
\end{tabular}

Figure 3 Meta-analysis of the relationship between LLL and BMS. CI, confidence interval; IV, inverse variance; SD, standard deviation; LLL, low-level laser; BMS, burning mouth syndrome.

the included studies $\left(\mathrm{I}^{2}=89 \% ; \mathrm{P}<0.00001\right)$ in Figure 2 . Therefore, we performed a sensitivity analysis by excluding one study at a time. The $\mathrm{I}^{2}$ was $74 \%, 93 \%, 93 \%$, and $85 \%$, respectively $(\mathrm{P}>0.0 .5)$. The results indicated that the sensitivity of heterogeneity was low and the meta-analysis was robust and credible.

\section{Adverse effects}

Of the 15 included trials, 5 reported no adverse reactions on patients undergoing LLL treatment $(24,26,30,32,36)$; however, the remaining 10 studies did not mention whether there were any adverse effects (Table 3) (20,21,25,27-29,31,33-35). Sugaya et al. reported that 2 and 5 participants were dropped from the experimental group and the control group, respectively, with no further explanation (Table 3) (21). Barbosa et al. mentioned that 11 patients did not complete the treatment for personal reasons unrelated to the study, and 1 patient with alpha-lipoic acid discontinued the study due to adverse headache and nausea (36).

\section{Risk of bias}

Risk of bias was assessed in 9 RCTs. Four RCTs showed a low overall risk of bias in Figure $3(20,21,24,32)$. However, 3 studies had an unclear overall risk of bias in Figure 3 (33-35). RCTs by Barbosa et al. and Vukoja et al. were marked as an overall high risk of bias in Figure $3(31,36)$.

\section{Discussion}

Most clinical trials reported that LLL treatment was effective and can reduce the symptoms of pain and burning sensation for patients with BMS. LLL treatment could be an alternative treatment option with the non-invasive and non-drug characters. However, successful treatment with LLL depends on the use of correct parameters and irradiation of LLL (37). Of 15 trials reviewed, LLL with $630 \mathrm{~nm}, 30 \mathrm{~mW}$ and $1 \mathrm{~J} / \mathrm{cm}^{2}$ showed the highest efficacy among 4 RCTs meta-analyzed. 
Patients with BMS have burning sensation or pain in the tongue or oral mucosa, without accompanying clinical and laboratory findings. The lack of unified criteria led the diagnosis of BMS difficult. In 1994, the International Association for the Study of Pain (IASP) defined BMS as burning tongue or other mucous membranes. It usually bilateral, dysgeusic taste, altered taste perception, dry mouth, denture intolerance (38). Two of 15 trials used IASP definition (20,34). In 2013, the International Classification of Headaches (ICH) addressed the definition of BMS as an inter-oral burning or dysaesthetic sensation, recurring daily for more than 2 hours per day over more than 3 months, without clinically evident causative lesions (39). This definition clearly describes the minimum time of symptom for BMS diagnosis. Two trials utilized ICH diagnostic criteria of BMS $(16,36)$. Although 3 of 15 trials cited neither IASP nor ICH definitions, the diagnosis of BMS criteria were described in their inclusion criteria $(25,30,33)$. Spanemberg et al. mentioned their enrolled BMS patients suffering oral burning/pain at least 4-6 months (33). In addition, 8 of 15 trials did not refer to the diagnostic criteria of BMS $(21,24,26-29,31,35)$. The lack of diagnostic criteria might made the studies inferior quality. As well, the difference of diagnosis criteria may lead to poor comparability of results.

In terms of gender distribution, the majority of the analyzed studies contained both females and males. Three studies, however, enrolled only female patients $(11,17,22)$. BMS is seen more frequently women, while men could also be diagnosed with BMS.

The desired outcome of LLL treatment for BMS was to reduce the symptom of pain or burning sensation. Of 15 trials reviewed, VAS and NRS were performed in $13(21,24-$ 26,28-36) and 2 studies (20,27), respectively. Evaluation of pain includes NRS, VAS, verbal rating scale (VRS), and faces pain rating scale (FPS) (40). VAS is similar to the NRS as it provides a measure of pain intensity and is accurate in assessment of the effects of a treatment, which is less influenced by the subjectivity of pain than is the VRS or FPS (40).

With a longer course and chronic persistence, BMS recurs easily and generally difficult to heal. LLL therapy may reduce acute and chronic pain by changing mitochondrial signaling and reducing ATP availability. It blocks and modulates neurotransmitters of $\mathrm{A} \delta$ and $\mathrm{C}$ nociceptors (21). LLL treatment of BMS has attracted attention as an approach for pain relief on patients with BMS. Most of trials applied LLL treatment at least 4 sessions (20,21,24-29,31-36). Sugaya et al. suggested that the effect of LLL therapy was temporary when a laser was applied in a single session, but these effects lasted longer when laser irradiation was performed in several sessions (21).

More RCTs are needed to draw a clear conclusion to provide evidence for optimized clinical management.

\section{Acknowledgments}

Funding: This work was supported by National Natural Science Foundation of China [No. 81671036], and the National Construction Project of Clinical Key Specialized Department [(2013)544].

\section{Footnote}

Conflicts of Interest: Both authors have completed the ICMJE uniform disclosure form (available at https://fomm. amegroups.com/article/view/10.21037/fomm.2019.10.02/ coif). The authors have no conflicts of interest to declare.

Ethical Statement: All the authors are accountable for all aspects of the work, and the questions related to the accuracy or integrity of any part of the work are appropriately investigated and resolved.

Open Access Statement: This is an Open Access article distributed in accordance with the Creative Commons Attribution-NonCommercial-NoDerivs 4.0 International License (CC BY-NC-ND 4.0), which permits the noncommercial replication and distribution of the article with the strict proviso that no changes or edits are made and the original work is properly cited (including links to both the formal publication through the relevant DOI and the license). See: https://creativecommons.org/licenses/by-nc-nd/4.0/.

\section{References}

1. Bender SD. Burning Mouth Syndrome. Dental clinics of North America 2018;62:585-96.

2. Klasser GD, Grushka M, Su N. Burning Mouth Syndrome. Oral Maxillofac Surg Clin North Am 2016;28:381-96.

3. Al-Maweri S, Javed F, Kalakonda B, et al. Efficacy of low level laser therapy in the treatment of burning mouth syndrome: A systematic review. Photodiagnosis Photodyn Ther 2017;17:188-93.

4. Meurman JH, Tarkkila L, Tiitinen A. The menopause and oral health. Maturitas 2009;63:56-62. 
5. Slebioda Z, Szponar E. Burning mouth syndrome - a common dental problem in perimenopausal women. Prz Menopauzalny 2014;13:198-202.

6. McMillan R, Forssell H, Buchanan JA, et al. Interventions for treating burning mouth syndrome. Cochrane Database Syst Rev 2016;11:CD002779.

7. Moghadam-Kia S, Fazel N. A diagnostic and therapeutic approach to primary burning mouth syndrome. Clin Dermatol 2017;35:453-60.

8. Coculescu EC, Radu A, Coculescu BI. Burning mouth syndrome: a review on diagnosis and treatment. J Med Life 2014;7:512-5.

9. Liu YF, Kim Y, Yoo T, et al. Burning mouth syndrome: a systematic review of treatments. Oral Dis 2018;24:325-34.

10. Silvestre FJ, Silvestre-Rangil J, Lopez-Jornet P. Burning mouth syndrome: a review and update. Rev Neurol 2015;60:457-63.

11. Marques NC, Neto NL, Rodini Cde O, et al. Low-level laser therapy as an alternative for pulpotomy in human primary teeth. Lasers Med Sci 2015;30:1815-22.

12. Vale FA, Moreira MS, de Almeida FC, et al. Low-level laser therapy in the treatment of recurrent aphthous ulcers: a systematic review. ScientificWorldJournal 2015;2015:150412.

13. Doshi S, Jain S, Hegde R. Effect of low-level laser therapy in reducing dentinal hypersensitivity and pain following periodontal flap surgery. Photomed Laser Surg 2014;32:700-6.

14. Li FJ, Zhang JY, Zeng XT, et al. Low-level laser therapy for orthodontic pain: a systematic review. Lasers Med Sci 2015;30:1789-803.

15. Gasperini G, Rodrigues de Siqueira IC, Rezende Costa L. Does low-level laser therapy decrease swelling and pain resulting from orthognathic surgery? Int J Oral Maxillofac Surg 2014;43:868-73.

16. Sezer U, Eltas A, Ustun K, et al. Effects of low-level laser therapy as an adjunct to standard therapy in acute pericoronitis, and its impact on oral health-related quality of life. Photomed Laser Surg 2012;30:592-7.

17. Nasri-Heir C, Zagury J, Thomas D, et al. Burning mouth syndrome: Current concepts. J Indian Prosthodont Soc 2015;15:300-7.

18. de Andrade AL, Bossini PS, Parizotto NA. Use of low level laser therapy to control neuropathic pain: A systematic review. J Photochem Photobiol B 2016;164:36-42.

19. Bittencourt MA, Paranhos LR, Martins-Filho PR. Lowlevel laser therapy for treatment of neurosensory disorders after orthognathic surgery: A systematic review of randomized clinical trials. Med Oral Patol Oral Cir Bucal 2017;22:780-7.

20. Arbabi-Kalati F, Bakhshani N,Rasti M. Evaluation of the efficacy of low-level laser in improving the symptoms of burning mouth syndrome. J Clin Exp Dent 2015;7:e524-e527.

21. Sugaya N, Silva E, Kato I, et al. Low Intensity laser therapy in patients with burning mouth syndrome: a randomized, placebo-controlled study. Braz Oral Res 2016;30:e108.

22. DerSimonian R, Laird N. Meta-analysis in clinical trials revisited. Contemporary clinical trials. Contemp Clin Trials 2015;45:139-45.

23. Liu J, Shi Q, Yang S, et al. The relationship between levels of salivary and serum interleukin-6 and oral lichen planus: A systematic review and meta-analysis. Journal of the American Dental Association. J Am Dent Assoc 2017;148:743-749.e9.

24. Arduino P, Cafaro A, Garrone M, et al. A randomized pilot study to assess the safety and the value of low-level laser therapy versus clonazepam in patients with burning mouth syndrome. Lasers Med Sci 2016;31:811-6.

25. Brailo V, Bosnjak A, Boras VV, et al. Laser acupuncture in the treatment of burning mouth syndrome: a pilot study. Acupunct Med 2013;31:453-4.

26. Kato I, Pellegrini V, Prates R, et al. Low-level laser therapy in burning mouth syndrome patients: a pilot study. Photomed Laser Surg 2010;28:835-9.

27. Romeo U, Del-Vecchio A, Capocci M, et al. The low level laser therapy in the management of neurological burning mouth syndrome. A pilot study. Ann Stomatol (Roma) 2010;1:14-8.

28. Santos-Lde F, Carvalho-Ade A, Leao L, et al. Effect of low-level laser therapy in the treatment of burning mouth syndrome: a case series. Photomed Laser Surg 2011;29:793-6.

29. Santos-Lde F, de-Andrade S, Nogueira G, et al. Phototherapy on the Treatment of Burning Mouth Syndrome: A Prospective Analysis of 20 Cases. Photochem Photobiol 2015;91:1231-6.

30. Yang H, Huang Y. Treatment of burning mouth syndrome with a low-level energy diode laser. Photomed Laser Surg 2011;29:123-5.

31. Vukoja D, Alajbeg I, Boras VV, et al. Is effect of low-level laser therapy in patients with burning mouth syndrome result of a placebo? Photomed Laser Surg 2011;29:647-8.

32. Valenzuela S, Lopez-Jornet P. Effects of low-level laser therapy on burning mouth syndrome. J Oral Rehabil 
2017;44:125-32.

33. Spanemberg J, JLopez-Lopez, de-Figueiredo M, et al. Efficacy of low-level laser therapy for the treatment of burning mouth syndrome: a randomized, controlled trial. J Biomed Opt 2015;20:098001.

34. Cui D, Zhang Y. Efficacy of low-level laser therapy in the treatment of burning mouth syndrome. Chinese Journal of Practical Stomatology 2017;10:158-62.

35. Pezelj-Ribaric S, Kqiku L, Brumini G, et al. Proinflammatory cytokine levels in saliva in patients with burning mouth syndrome before and after treatment with low-level laser therapy. Lasers Med Sci 2013;28:297-301.

36. Barbosa NG, Gonzaga AKG, de Sena Fernandes LL, et al. Evaluation of laser therapy and alpha-lipoic acid for

doi: $10.21037 /$ fomm.2019.10.02

Cite this article as: Sun C, Jiang WW. Low-level laser treatment of burning mouth syndrome: a systematic review and meta-analysis. Front Oral Maxillofac Med 2019;1:10. the treatment of burning mouth syndrome: a randomized clinical trial. Lasers Med Sci 2018;33:1255-62.

37. Zeller A. Burning tongue in a 47-year-old housewife. Praxis 2001:90:1103-5.

38. Merskey HE. Classification of chronic pain. Descriptions of chronic pain syndromes and definitions of pain terms. International Association for the Study of Pain. Pain Suppl 1986;Supplement 3:S1-226.

39. Headache Classification Committee of the International Headache Society (IHS). The international classification of headache disorders, 3 rd edition (beta version). Cephalagia 2013;33:629-808.

40. Thong ISK, Jensen MP, Miro J, et al. The validity of pain intensity measures: what do the NRS, VAS, VRS, and FPS-R measure? Scand J Pain 2018;18:99-107. 